\title{
GreekLex: A lexical database of Modern Greek
}

\author{
Maria Ktori, Walter J. B. van Heuven, and Nicola J. Pitchford \\ University of Nottingham, Nottingham, England
}

\begin{abstract}
To conduct experimental investigations into the orthographic processing of Modern Greek, information is needed about the lexical properties known to influence visual word recognition. In this article we introduce GreekLex, a lexical database for Modern Greek, which presents collectively for the first time a series of orthographic measures that can be used for psycholinguistic research. GreekLex consists of 35,304 Modern Greek words ranging in length from 1 to 22 letters, and for each word includes the following statistical information: word length, word-form frequency, lemma frequency, neighborhood density and frequency, transposition neighbors, and addition and deletion neighbors. Furthermore, type and token frequency measures of single letters and bigrams derived from the database are also available. The complete database can be accessed and downloaded freely from www.psychology.nottingham.ac.uk/GreekLex.
\end{abstract}

For the past 40 years, statistical information pertaining to English orthography has been available to researchers for psycholinguistic investigations of word processing (e.g., Baayen, Piepenbrock, \& Gulikers, 1995; Baayen, Piepenbrock, \& van Rijn, 1993; Coltheart, 1981; Kučera \& Francis, 1967; Mayzner \& Tresselt, 1965; Solso \& Juel, 1980). Lexical databases have been used extensively to match or manipulate stimuli on various lexical properties to investigate their influence on the processing of words in isolation and in sentence context. Similar databases have since become available for other Indo-European orthographies, such as French (Content, Mousty, \& Radeau, 1990; New, Pallier, Brysbaert, \& Ferrand, 2004), Dutch (Baayen et al., 1995; Baayen et al., 1993), German (Baayen et al., 1995; Baayen et al., 1993), and Spanish (Sebastián-Gallés, Marti, Cuetos, \& Carreiras, 2000). Until now, a comparable lexical database for Modern Greek words has not been available. Consequently, not many psycholinguistic studies of Modern Greek have been conducted and relatively little is known about the statistical orthographic properties of Modern Greek (Mikros, Hatzigeorgiu, \& Carayannis, 2005).

This apparent need for a lexical database based on the Modern Greek orthography, which would include a variety of orthographic measures, and would allow the user to select entries and match them across several criteria for experimental purposes, has led to the creation of GreekLex. GreekLex consists of 35,304 Modern Greek lemmas, for each of which we provide information on word length, written word-form and lemma frequency, and measures of orthographic similarity (i.e., neighborhood density and frequency, transposition neighbors, and addition and deletion neighbors). We also provide counts for the frequency with which single letters and bigrams occur in the 35,304 words listed in GreekLex. ${ }^{1}$
The orthographic measures provided for each Modern Greek word listed in GreekLex should enable researchers to conduct psycholinguistic investigations into the processing of Modern Greek orthography using a variety of experimental paradigms, such as lexical decision and word naming. Cross-linguistic investigations will also be possible between Modern Greek and other orthographies for which similar orthographic measures are available, because stimuli from different orthographies can be matched or manipulated for key lexical properties. In addition, GreekLex should be a useful resource for studies of bilingualism involving Modern Greek and other IndoEuropean orthographies, such as English.

Once experimental data is available on the lexical properties that influence the processing of Modern Greek words, attempts can be made to simulate these using computational models of orthographic processing (e.g., the interactive activation model, McClelland \& Rumelhart, 1981; MROM, Grainger \& Jacobs, 1996). Such investigations will not only shed light onto the cognitive representation and processing of Modern Greek orthography but will also elucidate the universality of models of visual word recognition and the factors that influence orthographic processing.

\section{Construction of GreekLex}

The first step in the construction of GreekLex involved the formation of a reference word vocabulary that contained information about written word frequency, from which a series of orthographic measures could then be extracted. This procedure involved drawing words from a reliable and widely used dictionary, namely the Lexicon of Common Modern Greek (Aristotle University of Thessaloniki, 1998). Each dictionary entry was then cross-checked against the Hellenic National Corpus (HNC) entries. HNC was developed by the Institute for Language and Speech

M. Ktori, Ipxmk2@nottingham.ac.uk 
Processing, founded in 1991 and based in Athens, Greece. The HNC is a corpus of written Modern Greek texts drawn from several media sources such as books, periodicals, and newspapers. It currently contains 46,890,207 words. ${ }^{2}$ Only entries that were listed in both the dictionary and the $\mathrm{HNC}$ were included in GreekLex.

A similar method of cross-checking a raw corpus against a reliable dictionary has also been used in the development of other orthographic databases for different languages (e.g., English-Davis, 2005; Spanish-Davis \& Perea, 2005; and Basque-Perea et al., 2006). This method serves to eliminate any entries in the corpus that are not contained in the dictionary, which may be cases of misspellings, nonlexical abbreviations, or nonalphabetic characters. According to Davis, the use of such a reference vocabulary for the calculation of measures of orthographic similarity (such as neighborhood statistics and bigram frequency) yields more representative estimates of the orthographic variability found in readers' lexicons. This is because a reader's lexicon is highly unlikely to contain all of the separate entries listed in large and overly comprehensive corpuses, such as the HNC.

There may be some limitations to this approach, however, because it produces a reference vocabulary that contains only entries that can be found in both the dictionary and the $\mathrm{HNC}$ corpus, and dictionary entries represent words in a conventional method - that is, as lemmas. Lemmas refer to the most basic form of words, irrespective of any grammatical inflections. For example, a noun is represented in the nominative singular form (e.g., apple) and does not include a separate entry for its plural form (e.g., apples). Likewise, a verb is represented in the infinitive form (e.g., eat) and not in its present- or past-participle forms (e.g., eating and ate). Consequently, GreekLex is made up of written words in their most basic form and does not include the inflected forms of Modern Greek words. In its present form, GreekLex would be of limited use for research focusing on the grammatical processing of the Greek orthography.

The HNC entries are classified in terms of word forms and lemmas, along with the corresponding written word frequency. Most psycholinguistic research uses frequency counts derived from lemma databases (e.g., Duyck, Desmet, Verbeke, \& Brysbaert, 2004). This is because it is commonly thought that the processing of written word forms involves partial activation of the corresponding lemma representation stored within the orthographic lexicon (e.g., Baayen, Dijkstra, \& Schreuder, 1997; New, Brysbaert, Segui, Ferrand, \& Rastle, 2004). Also, studies have shown that performance on visual lexical decision tasks and other tasks of visual word processing varies as a function of morphological family size (e.g., Feldman, Pnini, \& Frost, 1995; Hyönä \& Pollatsek, 1998; Schreuder \& Baayen, 1997). Because the lemma database is made up of the orthographic root morphemes (for example, the words do, does, doing, and done are represented together with their root morpheme $d o$ ), it provides unified frequency information that is more salient than frequency information for individual word forms (Vincent, Goldberg, \& Titone, 2006).

However, the use of lemma databases in psycholinguistic research has been criticized recently by Hofmann, Stenneken, Conrad, and Jacobs (2007), who suggested that lemma measures over- or underestimate the frequency of sublexical units (such as bigrams) that occur in inflective morphemes. According to Hofmann et al., word-form databases should be used instead of lemma databases in tasks that evaluate the use of language in its natural inflected form, such as tasks of sentence processing. Consequently, Hofmann et al. suggested that researchers should choose to use either a word-form or a lemma database, depending on the nature of the task to be used and the theoretical assumptions of a particular study. Because GreekLex reports frequency counts for both word forms and lemmas, researchers can decide which frequency counts to use from GreekLex for their research.

The filtering method outlined above resulted in a reference vocabulary of 35,304 entries, with the corresponding written word-form and lemma frequencies. Each entry in the reference vocabulary represents a different word; the words vary in grammatical class, and include nouns, verbs, adjectives, function words, and so on. For each lexical entry, the length in number of letters was calculated. Furthermore, based on lemma frequencies, a series of measures of orthographic similarity were calculated. These measures include neighborhood density (i.e., the number of words sharing all but one letter with a given word), neighborhood frequency (i.e., whether or not a given word has neighbors of higher frequency), transposition neighbors (i.e., the number of words that only differ from a given word by the order of two adjacent letters), addition neighbors (i.e., the number of words that only differ from a given word by the addition of a single letter), and deletion neighbors (i.e., the number of words that only differ from a given word by the deletion of a single letter). These measures of orthographic similarity have not been reported before for the Modern Greek orthography. In order to obtain these measures of orthographic similarity, diacritics were removed from the words. Abolishing diacritics was deemed necessary so as to achieve the purest orthographic form of each word listed in GreekLex. Modern Greek orthography utilizes two types of diacritics: the accent and the dieresis mark. The accent mark is placed above a vowel in polysyllabic words when written in lowercase, and it denotes the stressed syllable. However, when a word is written in uppercase, the accent mark is not used. For example, in lowercase letters, the English word "house" is written as $\sigma \pi i \tau \iota$, and in uppercase letters it is written as $\Sigma \Pi$ ITI. Therefore, all of the word entries in GreekLex were converted into uppercase letters. This resulted in some entries having duplicate mean-

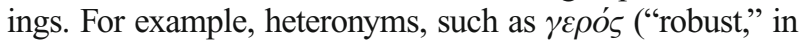
English) and $\gamma$ '́ $\rho \circ \varsigma$ ("old man," in English), became identical, ГЕPO $\Sigma$, when converted into uppercase letters. Also, some Greek words have more than one form of pronunciation, which is denoted when written in lowercase, such as $\gamma \omega v i \alpha$ and $\gamma \omega v i \alpha$ ("corner," in English), but when converted into uppercase the written forms become identical, $\Gamma \Omega$ NIA. In such instances, the summed written word frequency is reported in GreekLex. These instances were rare and apply to only $0.5 \%$ of the total entries listed in GreekLex. Finally, we used GreekLex to calculate the type and token frequencies for single letters and bigrams based on the lemma frequencies in GreekLex. The full lexicon can be downloaded at www.psychology.nottingham.ac.uk/GreekLex. 
In the following sections, we report summary statistics for each of the orthographic measures listed in the GreekLex database.

\section{Word Length}

Studies investigating the effects of word length on written word recognition are largely inconclusive (Balota, Cortese, Sergent-Marshall, Spieler, \& Yap, 2004; Hauk \& Pulvermüller, 2004; see New, Ferrand, Pallier, \& Brysbaert, 2006 , for a review) and may depend on the transparency of the orthography being investigated. For some transparent orthographies, such as Italian, effects of word length on written word recognition have been observed (Barca, Burani, \& Arduino, 2002). However, for other transparent orthographies, such as Spanish, the effects of word recognition on lexical processing appear to attenuate with reading skill (Acha \& Perea, 2008). Word length may therefore be an influential factor in the processing of Modern Greek orthography, because Modern Greek is a highly transparent orthography, although this has yet to be established.

The words listed in GreekLex vary in length, ranging from 1 to 22 letters. Figure 1 presents the distribution of words in the lexicon as a function of length. As illustrated in Figure 1, the majority of words in GreekLex are between 8 and 9 letters in length and constitute $14.13 \%$ and $14.23 \%$ of the lexicon, respectively. Approximately $54 \%$ of the words listed in GreekLex are between 7 and 10 letters in length, and the mean word length is 9.07 letters. To some extent, the mean length of words listed in GreekLex reflects the morphological properties of Modern Greek. As a synthetic language, words can be created in Modern Greek not only through the addition of a prefix or a suffix but also by compounding two or more roots into one (Mackridge, 1985).

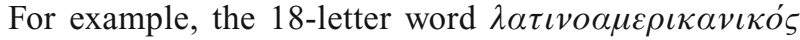

(masculine adjective for "Latin American") is formed by combining the word $\lambda \alpha \tau i v o \zeta$ ("Latin," in English), the word

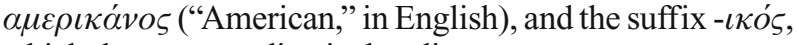
which denotes an adjectival ending.

\section{Written Word-Form and Lemma Frequency}

Words that occur frequently in written texts are recognized and named faster than words that appear less often (see Balota, 1994, and Monsell, 1991, for a review). For each word listed in GreekLex, word frequency is reported as the number of occurrences per million. As mentioned above, frequency counts were drawn from the HNC Web resource, which is published by the Institute for Language and Speech Processing based in Athens, Greece, and includes both the word-form and lemma written frequencies.

Because GreekLex represents essentially a subset of the words listed in the HNC, we sought to investigate the degree to which the database is a representative sample and whether it shares some principal properties with the larger HNC corpus. Hatzigeorgiu, Mikros, and Carayannis (2001) and Mikros et al. (2005) reported some basic quantitative characteristics of the Modern Greek language using the HNC. They showed that the distribution of the percentage of words in the $\mathrm{HNC}$ as a function of word length resembles a Poisson-like distribution. When a comparable distribution was drawn plotting the summed word frequency of GreekLex against word length, a distribution of the same nature emerged (see Figure 2). Moreover, three-letter words in GreekLex appeared to have the highest summed word frequency and about $50 \%$ of the summed word frequencies were accounted for by words with four or fewer letters. These figures are similar to those reported by Hatzigeorgiu et al. and Mikros et al., for the distribution of words in the first (13 million words) and second (43 million words) ver-

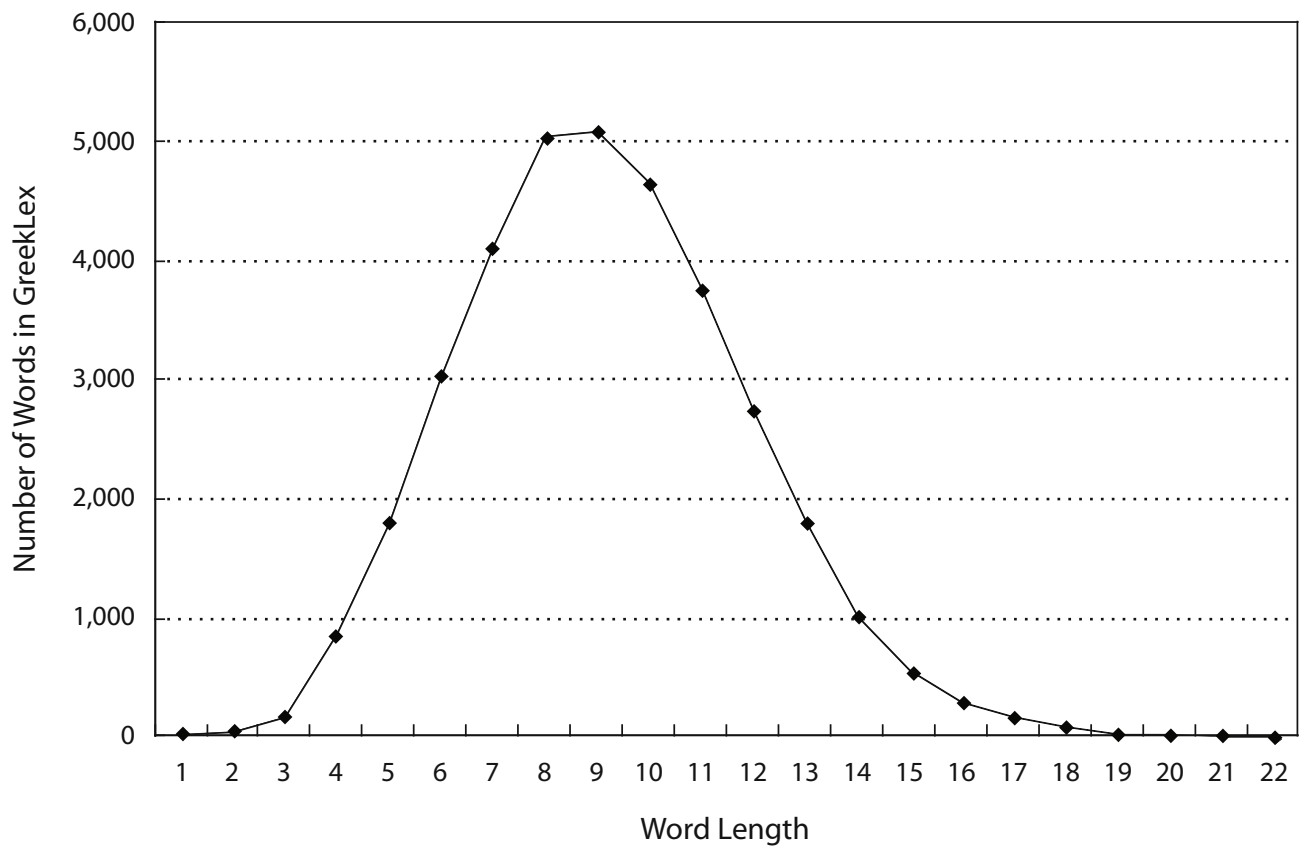

Figure 1. Distribution of word length for the 35,304 entries in GreekLex. 


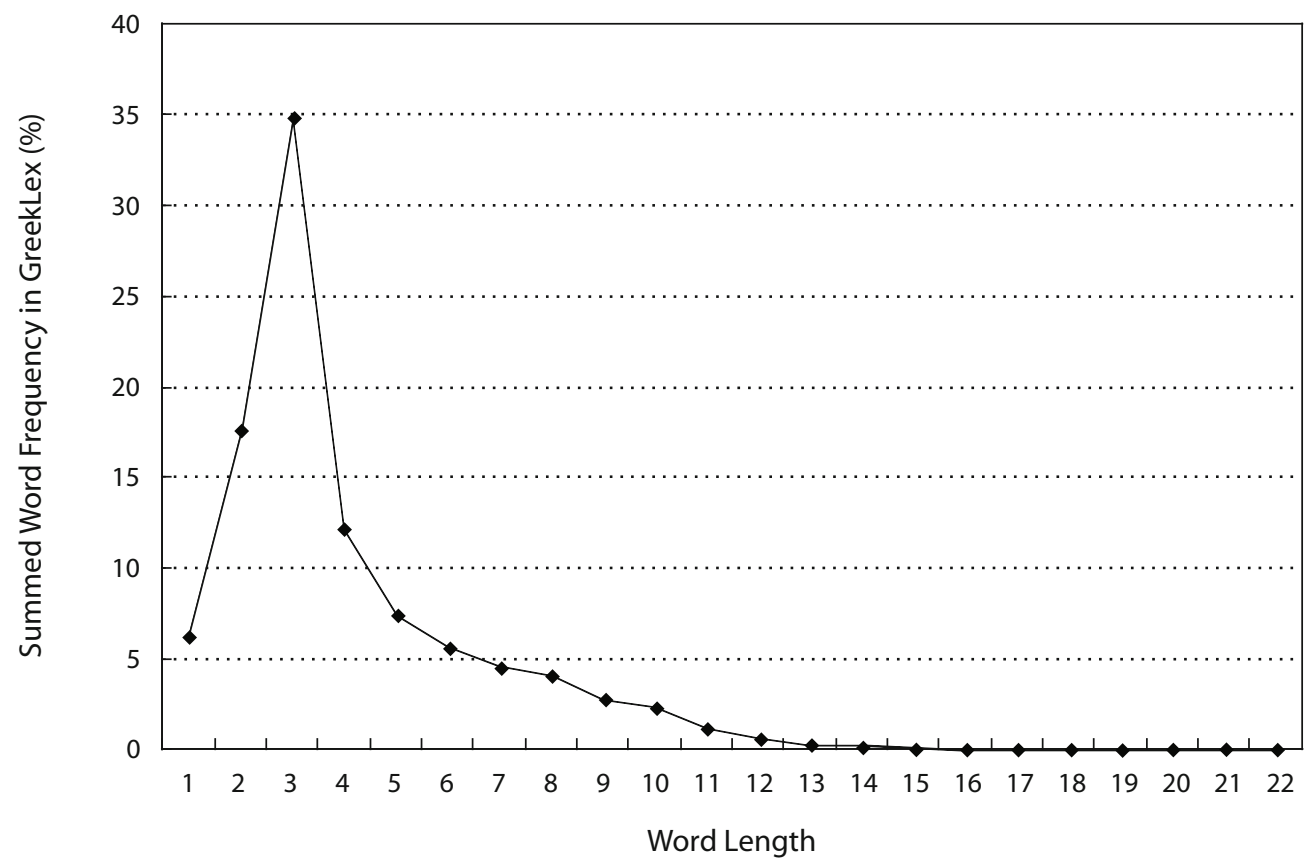

Figure 2. Percentage of summed word frequency in GreekLex as a function of word length.

sions of the HNC. In GreekLex, the average word in terms of frequency is 5.7 letters long, which is also comparable to the mean word length of 5.45 letters reported for the whole HNC (Hatzigeorgiu et al., 2001; Mikros et al., 2005). The striking resemblance of the GreekLex data shown in Figure 2 and the data reported for the HNC (Hatzigeorgiu et al., 2001; Mikros et al., 2005) demonstrates the degree to which GreekLex is comparable to the HNC. Seemingly, GreekLex is highly representative of the distribution of written words in Modern Greek orthography.

Entries in GreekLex have a written word-form frequency ranging from 0 to 34,185 occurrences per million, with a mean frequency of 15.27. The most frequent word is $k \alpha \iota$ and denotes the conjunction word "and" in English. The written lemma frequency in GreekLex varies between 0 and 168,561 occurrences per million, with a mean lemma frequency of 33.89. The word with the highest frequency is $o$, which denotes the masculine article in a nominative

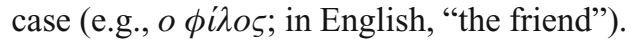

\section{Measures of Orthographic Similarity}

The processing of a written word leads to automatic activation of other orthographically similar words that, in turn, can affect lexical access (see, e.g., Andrews, 1997, for a review). Measures of orthographic similarity include: neighborhood density and frequency, transposition neighbors, and addition and deletion neighbors. Each of these measures was calculated for Modern Greek orthography using GreekLex.

Neighborhood density and neighborhood frequency. Coltheart, Davelaar, Jonasson, and Besner (1977) defined an orthographic neighbor as any word that differed from the target word by one letter position, while preserving all other letter positions. Thus, hand, lane, laid, and lend are some of the orthographic neighbors of the word land. Studies have shown that neighborhood density, which refers to the number of neighbors related to a word, influences performance on tasks of visual word recognition (see Andrews, 1997, and Perea \& Rosa, 2000, for reviews).

Another factor that appears to influence the strength of the neighborhood effect is the frequency of the orthographic neighbors in relation to a given word. For example, the frequency of the word land is 217 (as determined by Kučera \& Francis, 1967) and one of its orthographic neighbors, hand, has a higher frequency of 431 , whereas its orthographic neighbors, lane, laid, and lend, each have a lower frequency count of 30,77 , and 14 , respectively (data extracted from the MRC psycholinguistic database; Coltheart, 1981).

However, the direction of these effects can vary (e.g., Andrews, 1989, 1992, 1997; Carreiras, Perea, \& Grainger, 1997; Forster \& Shen, 1996; Grainger, 1990; Holcomb, Grainger, \& O'Rourke, 2002; Perea \& Pollatsek, 1998; Sears, Hino, \& Lupker, 1995; van Heuven, Dijkstra, \& Grainger, 1998). Furthermore, neighborhood density and frequency effects also appear to be task-dependent and affected by decision strategies (e.g., Carreiras et al., 1997; Grainger \& Jacobs, 1996).

Until the development of GreekLex, such investigations have not been possible for Modern Greek orthography, because counts of neighborhood density and frequency have not previously been available. Both neighborhood density and neighborhood frequency of each of the words listed in GreekLex were determined. For a given word, neighborhood density was determined by first listing and then counting the number of words in GreekLex that differed from the given word by a single letter in any position. Neighborhood frequency was then determined by counting the number of neighbors with a lemma frequency higher than that of the given word. 
Figure 3 shows the mean neighborhood density and frequency as a function of word length for word entries in GreekLex ranging from 3 to 12 letters, with a lemma frequency of above 1 per million. This length range was considered to provide a comprehensive representation of the statistical properties of Modern Greek orthography and is also the length range that is typically used in most psycholinguistic experiments (Davis \& Perea, 2005). Words with 4 letters appear to have the greatest mean number of orthographic neighbors (2.87) and the mean number of neighbors of higher frequency (1.32) from the entries listed in GreekLex.

Figure 4 gives information about the number of words in GreekLex with specific neighborhood density characteristics across word length (3-12 letters). Because a large percentage $(40.8 \%)$ of words listed in GreekLex had no orthographic neighbors, the number of these words was not plotted, so as to avoid distortion of scale on the $y$-axis. Instead, the number of words of a specified length with no orthographic neighbors is reported in text below each graph.

Figure 4 reveals a tendency for shorter words (ranging in length from three to five letters) to have more orthographic neighbors than longer words (with six or more letters). Furthermore, words with five letters or more have a higher incidence of no orthographic neighbors (the highest incidence being for nine-letter words) than words with five or fewer letters. The greatest number of orthographic neighbors (17) occurred for the four-letter word KAPA (the "head," in Ancient Greek). A similar relation between neighborhood density and word length has also been observed in other Indo-European orthographies, including Dutch, English, and German (Duyck et al., 2004). Future research can thus determine the effects of neighborhood density and frequency on the recognition of Modern Greek words.
Transposition neighbors. A transposition neighbor is a word that is identical with a given word except for the reversal of two adjacent letters in any position (Davis \& Taft, 2005). For example, the words martial and marital are transposition neighbors because they differ from each other only with respect to the order of two adjacent letters $(t i$ and $i t$ ). Interference effects of transposition neighbors have been found in lexical decision, word naming, and semantic categorization (e.g., Andrews, 1996; Chambers, 1979; Taft \& van Graan, 1998). Furthermore, in masked priming tasks, word recognition is faster when target words are preceded by a transposed neighbor prime word or nonword (e.g., Lupker, Perea, \& Davis, 2008; Perea \& Lupker, 2003a, 2003b). Recently, Perea and Lupker (2004) demonstrated that in Spanish, also a transparent orthography, the transposition neighbor advantage occurs only when the transposed letters are consonants and not when they are vowels. Thus, similar investigations in Modern Greek could determine how the nature of transposition-neighbor effects on written word recognition is mediated by orthographic transparency.

For each lexical entry in GreekLex the number of transposition neighbors was determined. The proportion of the words in GreekLex that have at least one transposition neighbor (e.g., АГРIA [in English, wILD] is a transposition neighbor of АРГІА [in English, HОLIDAY]) is $0.6 \%$. Four words were found to have two transposition neighbors (e.g., AIГA and ГAIA [in English, GOAT and EARTH, respectively] are both transposition neighbors of АГІА [in English, SAINT]).

Addition and deletion neighbors. Addition and deletion neighbors (also referred to as subset and superset words, respectively) represent two additional measures of orthographic similarity. An addition neighbor is a word that differs from the given word by the addition of a single

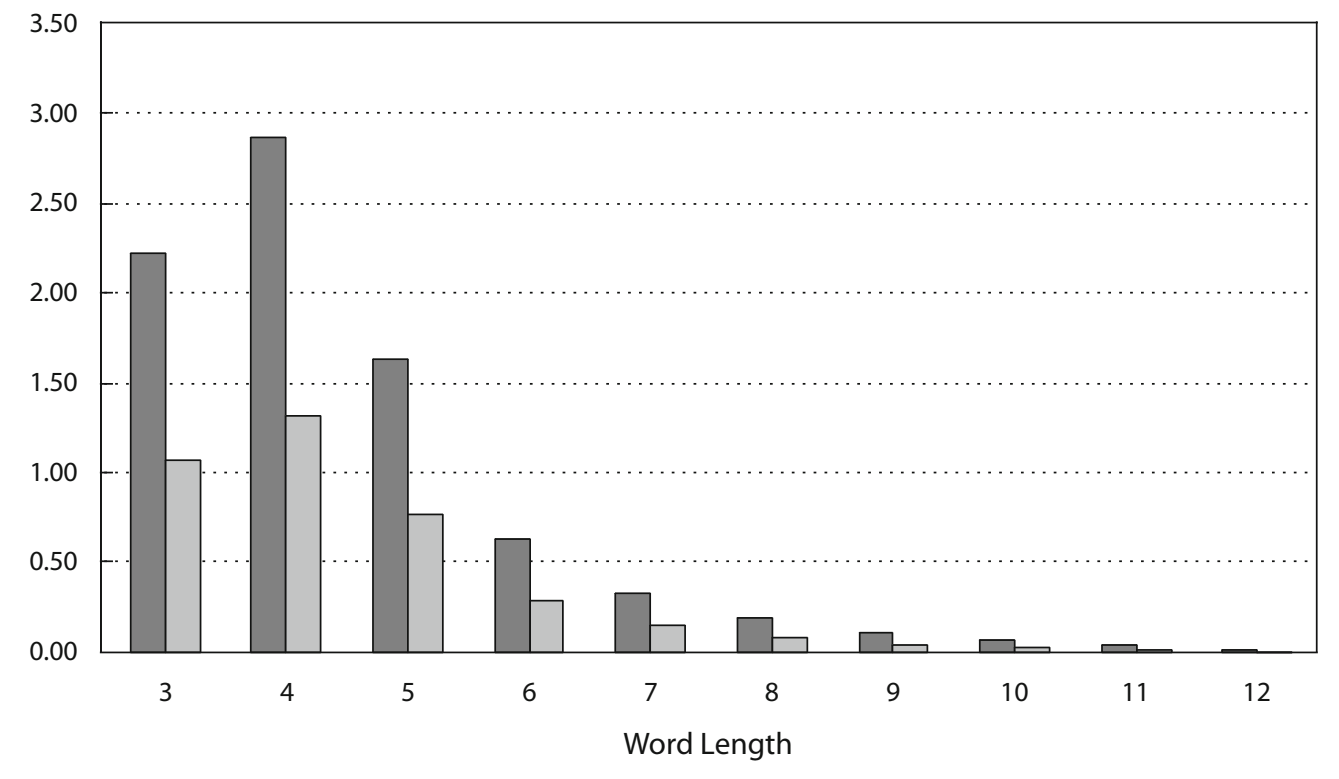

Mean neighborhood density $\square$ Mean neighborhood frequency

Figure 3. Distribution of mean neighborhood density and frequency as a function of word length (3-12 letters) for word entries in GreekLex with a lemma frequency of above 1 per million. 

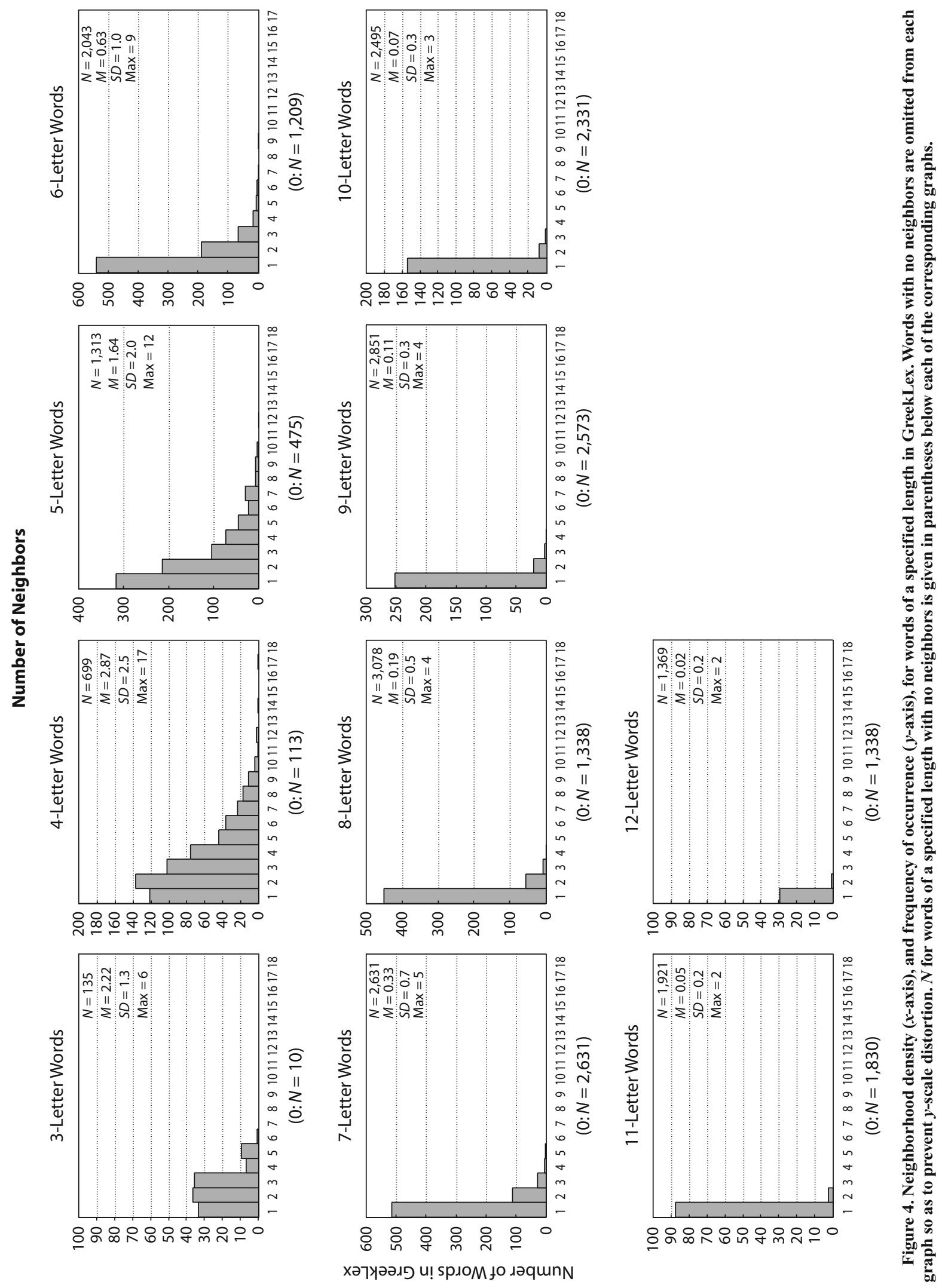
letter at any position. For example, the words smash and marsh are both addition neighbors of the word mash. A deletion neighbor of a word is a letter string that differs from the given word by the deletion of a single letter at any position. For example, the words sag and age are both deletion neighbors of the word sage. Recent investigations have shown that addition and deletion neighbors influence reaction times in lexical decision (Davis \& Perea, 2008; Davis \& Taft, 2005; De Moor \& Brysbaert, 2000; van Heuven \& Dijkstra, 2005) and semantic categorization (Bowers, Davis, \& Hanley, 2005). Such findings strengthen the argument that during reading, orthographically similar words are automatically activated (see also Lonke, Martensen, van Heuven, \& Sandra, in press). The above studies showed effects of addition and deletion neighbors in Dutch, English, and Spanish. However, whether or not similar effects can be found in Modern Greek needs to be investigated.

GreekLex words that differ from each other by the addition or deletion of a single letter at any position were calculated to determine addition and deletion neighbors, respectively. $8 \%$ of the word entries in GreekLex appear to have at least one addition neighbor (e.g., AГPIA [in English, wILD] is an addition neighbor of $\Gamma$ PIA [in English, OLD LADY]). The word APA (so, in English) is the word with the most (i.e., 14) addition neighbors. Similarly, 9.7\% of the GreekLex words have at least one deletion neighbor (e.g., $\Gamma \Omega$ NIA [in English, CORNER] is a deletion neighbor of A $\Omega$ NIA [in English, SUSPENSE]). The word АГPIA (WILD, in English) is the word with the most (i.e., four) deletion neighbors.

\section{Sublexical Frequency Measures: Letters and Bigrams}

A great deal of empirical and theoretical work has been dedicated to the investigation of the functional units that mediate the transition from the low-level visual description of a lexical stimulus to the actual lexical representation in long-term memory (e.g., Hofmann et al., 2007; Ziegler \& Goswami, 2005). Orthographic representations at the level of both individual letters and letter clusters (i.e., bigrams and trigrams) have been proposed to operate during orthographic processing (e.g., Humphreys, Evett, \& Quinlan, 1990; McClelland \& Rumelhart, 1981). Moreover, the effects of both letter frequency (e.g., Jones, 2001) and bigram frequency (e.g., Westbury \& Buchanan, 2002) on word processing suggest that these measures may affect experimental findings and prompt researchers to control for them when using letters and strings of letters as stimuli (Jones \& Mewhort, 2004).

GreekLex is the first database that includes both type and token frequency measures for letters and bigrams. A bigram is defined as an adjacent letter pair within a word. For example, the word АПОРІА ("question") has five bigrams: АП; ПО; OP; PI; IA. The type measure was determined by the number of words that contained a specific sublexical unit, whereas the token measure was obtained from the summed lemma frequencies of the words that contained a specific sublexical unit. These orthographic measures were derived from all the words in the GreekLex database across positions, and their calculations were based again on words in capital letters (see above).

Both type and token letter-frequency measures are given in Appendix A. Letter A has the highest type frequency, whereas letter $\mathrm{O}$ has the highest token frequency, and letter $\Psi$ has both the lowest type and token frequency in GreekLex. To examine the consistency of letter-frequency counts between GreekLex and the ones reported by Mikros et al. (2005) for the whole HNC, we computed the Pearson product-moment correlation coefficient. The correlation coefficient of token letter counts between GreekLex and an earlier version of $\mathrm{HNC}$ (with 33 million words) was $.91(p<.0001)$, demonstrating a high agreement of token letter frequency.

The type and token bigram frequencies collected from GreekLex are given in Appendix B. It is apparent from this predecessor-by-successor table that not all pairwise letter combinations are possible in the Modern Greek orthography. For example, letter pairs such as $\Gamma \mathrm{B}, \Delta \Theta$, and $\Psi \mathrm{M}$ are not found in the orthography of Modern Greek. Such letter pairs appear not to be legal in Modern Greek orthography and should thus be avoided in the construction of nonword stimuli. The type bigram frequency ranges from 1 to 12,308 and the token bigram frequency ranges from 0 to 190,273. The bigram $\mathrm{O} \Sigma$ has the greatest number of appearances and the highest summed lemma frequency in GreekLex.

\section{Summary and Future Development}

Here we have introduced GreekLex, a lexical database consisting of 35,304 Modern Greek words, which, for the first time, includes collectively a series of orthographic measures based on Modern Greek orthography. GreekLex should thus enable more stringent control than has previously been possible over the selection of word stimuli, and the creation of nonword stimuli, for use in psycholinguistic research on word processing. The process of item construction for psycholinguistic research on the processing of written words is not a trivial matter. As Duyck et al. (2004) have pointed out,

to be able to draw valid and general conclusions on the basis of the experiment's outcome, the selection of words has to be performed with the utmost care; items have to be manipulated adequately on the experimental variables under scrutiny, and items in different conditions have to be matched appropriately on potentially confounding factors. (p. 488)

GreekLex is the first database that will allow such manipulations and matching procedures to be made on item construction in Modern Greek. Future developments of GreekLex involve the inclusion of syntactic and phonological information as well as the calculation of syllable frequency counts that would enable further insight into the orthographic processing of Modern Greek.

\section{AUTHOR NOTE}

Correspondence concerning this article should be addressed to M. Ktori, School of Psychology, University of Nottingham, University Park, Nottingham NG7 2RD, England (e-mail: 1pxmk2@nottingham.ac.uk). 


\section{REFERENCES}

Acha, J., \& Perea, M. (2008). The effects of length and transposedletter similarity in lexical decision: Evidence with beginning, intermediate, and adult readers. British Journal of Psychology, 99, 245-264.

ANDREws, S. (1989). Frequency and neighborhood effects on lexical access: Activation or search? Journal of Experimental Psychology: Learning, Memory, \& Cognition, 15, 802-814.

ANDREws, S. (1992). Frequency and neighborhood effects on lexical access: Lexical similarity or orthographic redundancy? Journal of Experimental Psychology: Learning, Memory, \& Cognition, 18, 234-254.

ANDREWS, S. (1996). Lexical retrieval and selection processes: Effects of transposed-letter confusability. Journal of Memory \& Language, 35, 775-800.

ANDREws, S. (1997). The effect of orthographic similarity on lexical retrieval: Resolving neighborhood conflicts. Psychonomic Bulletin \& Review, 4, 439-461.

Aristotle University of Thessaloniki, Institute for Modern Greek Studies (1998). Lexicon of common Modern Greek. Thessaloniki: Author.

BaAyen, R. H., Dijkstra, T., \& Schreuder, R. (1997). Singulars and plurals in Dutch: Evidence for a parallel dual-route model. Journal of Memory \& Language, 37, 94-117.

Batyen, R. H., Piepenbrock, R., \& Gulikers, L. (1995). The CELEX lexical database (Release 2) [CD-ROM]. Philadelphia: Linguistic Data Consortium, University of Pennsylvania [Distributor].

BaAyen, R. H., Piepenbrock, R., \& van Rijn, H. (1993). The CELEX lexical database (Release 1) [CD-ROM]. Philadelphia: Linguistic Data Consortium, University of Pennsylvania [Distributor].

Balota, D. A. (1994). Visual word recognition: The journey from features to meaning. In M. A. Gernsbacher (Ed.), Handbook of psycholinguistics (pp. 303-358). San Diego: Academic Press.

Balota, D. A., Cortese, M. J., Sergent-Marshall, S. D., Spieler, D. H., \& YAP, M. J. (2004). Visual word recognition of single syllable words. Journal of Experimental Psychology: General, 133, 283-316.

Barca, L., Burani, C., \& Arduino, L. S. (2002). Word naming times and psycholinguistic norms for Italian nouns. Behavior Research Methods, Instruments, \& Computers, 34, 424-434.

Bowers, J. S., Davis, C. J., \& Hanley, D. A. (2005). Automatic semantic activation of embedded words: Is there a "hat" in "that"? Journal of Memory \& Language, 52, 131-143.

Carreiras, M., Perea, M., \& Grainger, J. (1997). Effects of the orthographic neighborhood in visual word recognition: Cross-task comparisons. Journal of Experimental Psychology: Learning, Memory, \& Cognition, 23, 857-871

Chambers, S. M. (1979). Letter and order information in lexical access. Journal of Verbal Learning \& Verbal Behavior, 18, 225-241.

Coltheart, M. (1981). The MRC psycholinguistic database. Quarterly Journal of Experimental Psychology, 33A, 497-505.

Coltheart, M., Besner, D., Jonasson, J. T., \& Davelaar, E. (1979). Phonological encoding in the lexical decision task. Quarterly Journal of Experimental Psychology, 31, 489-507.

Coltheart, M., Davelaar, E., Jonasson, J. T., \& Besner, D. (1977). Access to the internal lexicon. In S. Dornic (Ed.), Attention and performance VI (pp. 535-555). Hillsdale, NJ: Erlbaum.

Content, A., Mousty, P., \& Radeau, M. (1990). BRULEX: Une base de données lexicales informatisée pour le français écrit et parlé [A lexical computerized database for written and spoken French]. L'Année Psychologique, 90, 551-566.

DAvIs, C. J. (2005). N-Watch: A program for deriving neighborhood size and other psycholinguistic statistics. Behavior Research Methods, 37, 65-70.

DAVIS, C. J., \& Perea, M. (2005). BuscaPalabras: A program for deriving orthographic and phonological neighborhood statistics and other psycholinguistic indices in Spanish. Behavior Research Methods, 37, 665-671.

Davis, C. J., \& PerEa, M. (2008). Re(de)fining the orthographic neighbourhood: Evidence for the similarity of addition and deletion neighbours in Spanish. Manuscript submitted for publication.

DAVIS, C. J., \& TAFT, M. (2005). More words in the neighborhood: Interference in lexical decision due to deletion neighbors. Psychonomic Bulletin \& Review, 12, 904-910.

De Moor, W., \& Brysbaert, M. (2000). Neighborhood-frequency ef- fects when primes and targets are of different lengths. Psychological Research, 63, 159-162.

Duyck, W., Desmet, T., Verbeke, L. P. C., \& Brysbaert, M. (2004). WordGen: A tool for word selection and nonword generation in Dutch, English, German, and French. Behavior Research Methods, Instruments, \& Computers, 36, 488-499.

Feldman, L. B., Frost, R., PNini, T. \& (1995). Decomposing words into their constituent morphemes: Evidence from English and Hebrew. Journal of Experimental Psychology: Learning, Memory, \& Cognition, 21, 947-960.

Forster, K. I., \& SHEN, D. (1996). No enemies in the neighborhood: Absence of inhibitory effects in lexical decision and semantic categorization. Journal of Experimental Psychology: Learning, Memory, \& Cognition, 22, 696-713.

GRAINGER, J. (1990). Word frequency and neighborhood frequency effects in lexical decision and naming. Journal of Memory \& Language, 29, 228-244.

GRAINGER, J., \& JACOBS, A. (1996). Orthographic processing in visual word recognition: A multiple readout model. Psychological Review, 103, 518-565

Hatzigeorgiu, N., Mikros, G., \& Carayannis, G. (2001). Word length, word frequencies and Zipf's Law in the Greek language. Journal of Quantitative Linguistics, 8, 175-185.

Hauk, O., \& Pulvermüller, F. (2004). Effects of word length and frequency on the human event-related potential. Clinical Neurophysiology, 115, 1090-1103.

Hofmann, M. J., Stenneken, P., Conrad, M., \& Jacobs, A. M. (2007). Sublexical frequency measures for orthographic and phonological units in German. Behavior Research Methods, 39, 620-629.

Holcomb, P. J., Grainger, J., \& O’Rourke, T. (2002). An electrophysiological study of the effects of orthographic neighborhood size on printed word recognition. Journal of Cognitive Neuroscience, 14, 938-950.

Humphreys, G. W., Evett, L. J., \& Quinlan, P. T. (1990). Orthographic processing in visual word recognition. Cognitive Psychology, 22, 517-560

HyöNä, J., \& Pollatsek, A. (1998). Reading Finnish compound words: Eye fixations are affected by component morphemes. Journal of Experimental Psychology: Human Perception \& Performance, 24, 1612-1627.

JoNES, M. N. (2001). T-REX: A template-resonance excitation model of single letter classification. Unpublished master's thesis, Queen's University at Kingston, Ontario, Canada.

Jones, M. N., \& Mewhort, D. J. K. (2004). Case-sensitive letter and bigram frequency counts from large-scale English corpora. Behavior Research Methods, Instruments, \& Computers, 36, 388-396.

Kučera, H., \& Francis, W. N. (1967). Computational analysis of present-day American English. Providence, RI: Brown University Press.

Lonke, M., Martensen, H., van Heuven, W. J. B., \& Sandra, D. (in press). Who is dominating the Dutch neighbourhood? On the role of subsyllabic units in Dutch nonword reading. Quarterly Journal of Experimental Psychology.

LuPKer, S. J., Perea, M., \& Davis, C. J. (2008). Transposed-letter effects: Consonants, vowels and letter frequency. Language \& Cognitive Processes, 23, 93-116.

MACKRIDGE, P. (1985). The Modern Greek language: A descriptive analysis of standard Modern Greek. Oxford: Oxford University Press.

Mayzner, M. S., \& Tresselt, M. E. (1965). Tables of single-letter and digram frequency counts for various word-length and letter-position combinations. Psychonomic Monograph Supplements, 1(Whole No. 2), 13-32.

McClelland, J. L., \& Rumelhart, D. E. (1981). An interactive activation model of context effects in letter perception: Part 1. An account of basic findings. Psychological Review, 88, 375-405.

Mikros, G., Hatzigeorgiu, N., \& CarayanNis, G. (2005). Basic quantitative characteristics of the Modern Greek language using the Hellenic National Corpus. Journal of Quantitative Linguistics, 12, 167-184.

Monsell, S. (1991). The nature and locus of word frequency effects in reading. In D. Besner \& G. W. Humphreys (Eds.), Basic processes in reading: Visual word recognition (pp. 148-197). Hillsdale, NJ: Erlbaum.

New, B., Brysbaert, M., Segui, J., Ferrand, L., \& Rastle, K. (2004). 
The processing of singular and plural nouns in French and English. Journal of Memory \& Language, 51, 568-585.

New, B., Ferrand, L., Pallier, C., \& Brysbaert, M. (2006). Reexamining the word length effect in visual word recognition: New evidence from the English Lexicon Project. Psychonomic Bulletin \& Review, 13, 45-52.

New, B., Pallier, C., Brysbaert, M., \& Ferrand, L. (2004). Lexique 2: A new French lexical database. Behavior Research Methods, Instruments, \& Computers, 36, 516-524.

Perea, M., \& LupKer, S. J. (2003a). Does jugde activate COURT? Transposed-letter similarity effects in masked associative priming. Memory \& Cognition, 31, 829-841.

Perea, M., \& LupKer, S. J. (2003b). Transposed-letter confusability effects in masked form priming. In S. Kinoshita \& S. J. Lupker (Eds.), Masked priming: State of the art (pp. 97-120). Hove, U.K.: Psychology Press.

Perea, M., \& Lupker, S. J. (2004). Can CANISO activate CASINO? Transposed-letter similarity effects with nonadjacent letter positions. Journal of Memory \& Language, 51, 231-246.

Perea, M., \& Pollatsek, A. (1998). The effects of neighborhood frequency in reading and lexical decision. Journal of Experimental Psychology: Human Perception \& Performance, 24, 767-779.

Perea, M., \& Rosa, E. (2000). The effects of orthographic neighborhood in reading and laboratory word identification tasks: A review. Psicológica, 21, 327-340.

Perea, M., Urkia, M., Davis, C. J., Agirre, A., Laseka, E., \& CarreiRAS, M. (2006). E-Hitz: A word frequency list and a program for deriving psycholinguistic statistics in an agglutinative language (Basque). Behavior Research Methods, 38, 610-615.

SCHREUdER, R., \& BAAYEN, R. H. (1997). How complex simplex words can be. Journal of Memory \& Language, 37, 118-139.

SEARS, C. R., HINO, Y., \& LUPKER, S. J. (1995). Neighborhood frequency and neighborhood size effects in visual word recognition. Journal of Experimental Psychology: Human Perception \& Performance, 21, 876-900.

Sebastián-Gallés, N., Marti, M. A., Cuetos, F., \& Carreiras, M. (2000). LEXESP: Léxico informarizado del español. Barcelona: Edicions de la Universitat de Barcelona.

Seidenberg, M. S., Waters, G. S., Barnes, M. A., \& Tanenhaus,
M. K. (1984). When does irregular spelling or pronunciation influence word recognition? Journal of Verbal Learning \& Verbal Behavior, 23, 383-404.

Solso, R. L., \& Juel, C. L. (1980). Positional frequency and versatility of bigrams for two- through nine-letter English words. Behavior Research Methods \& Instrumentation, 12, 297-343.

TAFT, M., \& VAN GRAAN, F. (1998). Lack of phonological mediation in a semantic categorization task. Journal of Memory \& Language, 38, 203-224.

van Heuven, W. J. B., \& Dijkstra, T. (2005). Extended neighborhood effects in visual word recognition. Poster presented at the 14th Meeting of the European Society for Cognitive Psychology, Leiden, The Netherlands.

van Heuven, W. J. B., Dijkstra, T., \& Grainger, J. (1998). Orthographic neighborhood effects in bilingual word recognition. Journal of Memory \& Language, 39, 458-483.

Vincent, R. D., Goldberg, Y. K., \& Titone, D. A. (2006). Anagram software for cognitive research that enables specification of psycholinguistic variables. Behavior Research Methods, 38, 196-201.

Westbury, C., \& Buchanan, L. (2002). The probability of the least likely non-length-controlled bigram affects lexical decision reaction times. Brain \& Language, 81, 66-78.

Ziegler, J. C., \& Goswami, U. (2005). Reading acquisition, developmental dyslexia, and skilled reading across languages: A psycholinguistic grain size theory. Psychological Bulletin, 131, 3-29.

\section{NOTES}

1. For deep orthographies, such as English, regularity and consistency are other orthographic properties that have been shown to influence word reading (Coltheart, Besner, Jonasson, \& Davelaar, 1979; Seidenberg, Waters, Barnes, \& Tanenhaus, 1984). These lexical properties should be of little relevance to the orthographic processing of Modern Greek, however, because Modern Greek is a very transparent orthography, with highly consistent mappings between graphemes and phonemes.

2. The Hellenic National Corpus is available at the following Web address: hnc.ilsp.gr/. The HNC is a growing corpus and is constantly being updated with the addition of new documents. The HNC was used in the construction of GreekLex during the period of January to March 2007.

\begin{tabular}{|c|c|c|}
\hline \multicolumn{3}{|c|}{$\begin{array}{c}\text { APPENDIXA } \\
\text { Type and Token Letter Frequency } \\
\text { in GreekLex }\end{array}$} \\
\hline Letter & $\begin{array}{c}\text { Type } \\
\text { Frequency }\end{array}$ & $\begin{array}{c}\text { Token } \\
\text { Frequency }\end{array}$ \\
\hline $\mathrm{O}$ & 36,920 & 579,586 \\
\hline A & 39,008 & 528,074 \\
\hline E & 17,693 & 479,883 \\
\hline I & 28,715 & 420,299 \\
\hline$\Sigma$ & 29,067 & 399,023 \\
\hline$\Omega$ & 9,534 & 339,754 \\
\hline $\mathrm{T}$ & 20,022 & 263,979 \\
\hline$\Gamma$ & 6,639 & 246,370 \\
\hline M & 12,982 & 229,767 \\
\hline $\mathrm{P}$ & 19,064 & 214,218 \\
\hline $\mathrm{N}$ & 13,785 & 212,775 \\
\hline$\Pi$ & 12,318 & 210,809 \\
\hline $\mathrm{Y}$ & 11,505 & 210,798 \\
\hline $\mathrm{K}$ & 14,801 & 193,147 \\
\hline $\mathrm{H}$ & 11,680 & 168,553 \\
\hline$\Lambda$ & 11,964 & 136,757 \\
\hline$\Delta$ & 6,036 & 89,962 \\
\hline $\mathrm{X}$ & 3,955 & 60,211 \\
\hline$\Theta$ & 3,143 & 50,158 \\
\hline$\Phi$ & 4,640 & 42,216 \\
\hline B & 3,046 & 32,574 \\
\hline $\mathrm{Z}$ & 2,465 & 24,308 \\
\hline$\Xi$ & 1,853 & 17,669 \\
\hline $\bar{\Psi}$ & 731 & 4,932 \\
\hline
\end{tabular}


APPENDIX B

Predecessor-by-Successor Table of Type and Token Bigram Frequencies in GreekLex

\begin{tabular}{|c|c|c|c|c|c|c|c|c|c|c|c|}
\hline Predecessor & A & $\mathrm{B}$ & $\Gamma$ & $\Delta$ & $\mathrm{E}$ & Z & $\mathrm{H}$ & $\Theta$ & $\mathrm{I}$ & K & $\Lambda$ \\
\hline \multicolumn{12}{|c|}{ Type Bigram Frequency } \\
\hline $\mathrm{A}$ & & 579 & 1,442 & 828 & 165 & 721 & 37 & 707 & 2,072 & 1,813 & 2,534 \\
\hline $\mathrm{B}$ & 896 & 7 & 28 & 41 & 272 & 1 & 121 & & 446 & & 192 \\
\hline$\Gamma$ & 740 & & 313 & 43 & 631 & & 328 & & 1,086 & 587 & 173 \\
\hline$\Delta$ & 857 & & & & 725 & & 526 & & 2,102 & & \\
\hline $\mathrm{E}$ & 205 & 183 & 455 & 186 & 6 & 141 & 14 & 177 & 2,098 & 1,022 & 1,293 \\
\hline $\mathrm{Z}$ & 237 & & & & 127 & & 117 & & 191 & & 1 \\
\hline $\mathrm{H}$ & & 14 & 274 & 92 & 3 & 3 & & 137 & 3 & 156 & 490 \\
\hline$\Theta$ & 343 & & & & 790 & & 403 & & 191 & & 63 \\
\hline I & 5,380 & 288 & 413 & 1,097 & 421 & 922 & 221 & 270 & 41 & 4,903 & 692 \\
\hline $\mathrm{K}$ & 3,103 & 24 & 2 & 53 & 748 & 2 & 428 & 19 & 971 & 96 & 572 \\
\hline$\Lambda$ & 2,225 & 26 & 34 & 5 & 1,423 & 1 & 1,078 & 10 & 2,122 & 90 & 665 \\
\hline M & 4,022 & 219 & & 1 & 1,645 & & 554 & & 1,164 & 1 & \\
\hline $\mathrm{N}$ & 2,042 & & 1 & 310 & 1,078 & 19 & 912 & 283 & 2,024 & 8 & 1 \\
\hline$\Xi$ & 331 & & & & 518 & & 201 & & 386 & & \\
\hline $\mathrm{O}$ & 132 & 458 & 1,598 & 913 & 215 & 86 & 131 & 304 & 1,246 & 1,227 & 2,157 \\
\hline$\Pi$ & 2,622 & & & & 1,475 & & 300 & & 1,411 & 1 & 796 \\
\hline $\mathrm{P}$ & 3,881 & 83 & 499 & 179 & 1,239 & 6 & 682 & 123 & 3,801 & 198 & 52 \\
\hline$\Sigma$ & 938 & 87 & 9 & 29 & 377 & & 2,077 & 197 & 1,548 & 888 & 32 \\
\hline $\mathrm{T}$ & 3,522 & & & & 1,638 & 200 & 2,531 & 1 & 3,872 & 1 & 34 \\
\hline $\mathrm{Y}$ & 221 & 165 & 493 & 320 & 53 & 92 & 52 & 264 & 40 & 421 & 1,024 \\
\hline$\Phi$ & 802 & & 1 & & 354 & & 242 & 80 & 782 & 1 & 127 \\
\hline $\mathrm{X}$ & 733 & & & & 365 & & 266 & 56 & 467 & & 84 \\
\hline$\Psi$ & 91 & & & & 78 & & 182 & & 157 & & \\
\hline$\Omega$ & 16 & 21 & 166 & 233 & 1 & 4 & 9 & 45 & 36 & 45 & 148 \\
\hline \multicolumn{12}{|c|}{ Token Bigram Frequency } \\
\hline A & & 3,312 & 13,618 & 7,926 & 1,036 & 7,597 & 138 & 10,245 & 84,942 & 13,337 & 26,972 \\
\hline B & 12,438 & 139 & 468 & 331 & 4,143 & 0 & 771 & & 2,009 & & 3,538 \\
\hline$\Gamma$ & 8,768 & & 2,291 & 69 & 6,746 & & 4,303 & & 23,538 & 4,905 & 618 \\
\hline$\Delta$ & 4,853 & & & & 18,509 & & 9,945 & & 33,344 & & \\
\hline $\mathrm{E}$ & 2,730 & 2,394 & 166,483 & 5,975 & 4 & 915 & 28 & 2,410 & 46,453 & 11,579 & 17,622 \\
\hline $\mathrm{Z}$ & 754 & & & & 299 & & 2,464 & & 1,065 & & 4 \\
\hline $\mathrm{H}$ & & 51 & 5,217 & 680 & 2 & 12 & & 1,797 & 12 & 1,195 & 5,311 \\
\hline$\Theta$ & 11,367 & & & & 17,740 & & 3,016 & & 1,309 & & 658 \\
\hline I & 64,032 & 2,714 & 4,193 & 12,494 & 3,964 & 11,120 & 1,346 & 3,157 & 220 & 61,316 & 4,925 \\
\hline $\mathrm{K}$ & 70,156 & 67 & 1 & 1,014 & 9,280 & 1 & 7,453 & 448 & 4,809 & 482 & 4,904 \\
\hline$\Lambda$ & 16,069 & 128 & 93 & 25 & 20,553 & 0 & 13,325 & 343 & 18,529 & 290 & 15,002 \\
\hline M & 54,861 & 4,485 & & 0 & 47,744 & & 9,525 & & 10,910 & 0 & \\
\hline $\mathrm{N}$ & 54,425 & & 0 & 3,562 & 11,600 & 50 & 10,058 & 2,105 & 17,062 & 11 & 3 \\
\hline$\Xi$ & 2,783 & & & & 3,332 & & 5,187 & & 2,831 & & \\
\hline $\mathrm{O}$ & 319 & 4,028 & 11,121 & 7,495 & 2,240 & 561 & 1,463 & 2,446 & 23,430 & 7,631 & 28,212 \\
\hline$\Pi$ & 30,396 & & & & 18,774 & & 4,298 & & 20,853 & 0 & 7,467 \\
\hline $\mathrm{P}$ & 41,029 & 305 & 11,259 & 787 & 13,050 & 2 & 6,250 & 1,360 & 41,288 & 1,943 & 41 \\
\hline$\Sigma$ & 4,782 & 557 & 30 & 584 & 10,478 & & 38,854 & 1,657 & 16,312 & 6,735 & 239 \\
\hline $\mathrm{T}$ & 40,732 & & & & 23,489 & 220 & 34,204 & 2 & 54,114 & 2 & 390 \\
\hline $\mathrm{Y}$ & 1,073 & 2,258 & 4,675 & 1,153 & 182 & 979 & 626 & 4,111 & 141 & 1,899 & 6,229 \\
\hline$\Phi$ & 7,618 & & 1 & & 5,930 & & 2,838 & 760 & 3,795 & 1 & 185 \\
\hline$X$ & 4,801 & & & & 6,638 & & 4,773 & 1,231 & 4,746 & & 164 \\
\hline$\Psi$ & 165 & & & & 267 & & 3,533 & & 243 & & \\
\hline$\Omega$ & 81 & 185 & 1,405 & 605 & 0 & 80 & 734 & 920 & 276 & 283 & 499 \\
\hline
\end{tabular}


APPENDIX B (Continued)

\begin{tabular}{|c|c|c|c|c|c|c|c|c|c|c|c|c|}
\hline M & $\mathrm{N}$ & $\Xi$ & $\mathrm{O}$ & $\Pi$ & $\mathrm{P}$ & $\Sigma$ & $\mathrm{T}$ & $\mathrm{Y}$ & $\Phi$ & $\mathrm{X}$ & $\Psi$ & $\Omega$ \\
\hline \multicolumn{13}{|c|}{ Type Bigram Frequency (Continued) } \\
\hline 1,436 & $\begin{array}{r}4,068 \\
1\end{array}$ & 318 & $\begin{array}{r}95 \\
600\end{array}$ & 1,754 & $\begin{array}{r}3,802 \\
285\end{array}$ & 3,388 & 3,342 & $\begin{array}{r}619 \\
54\end{array}$ & 1,004 & 620 & 81 & $\begin{array}{r}142 \\
99\end{array}$ \\
\hline 205 & 203 & 1 & 912 & & 641 & & & 200 & & 94 & & 482 \\
\hline 3 & 2 & & 952 & & 433 & & & 270 & & & & 165 \\
\hline 771 & 1,714 & 586 & 302 & 1,092 & 2,641 & 827 & 1,356 & 1,604 & 389 & 248 & 58 & 180 \\
\hline 1 & 3 & & 339 & & & & & 46 & & & & 1,359 \\
\hline 1,062 & 381 & 35 & 6 & 95 & 728 & 3,059 & 1,528 & 1 & 96 & 140 & 43 & 1 \\
\hline 134 & 70 & & 405 & & 321 & & & 260 & & & & 160 \\
\hline 948 & 1,470 & 57 & 3,025 & 407 & 656 & 3,466 & 969 & 8 & 185 & 325 & 48 & 552 \\
\hline 51 & 59 & & 6,111 & 59 & 860 & 23 & 831 & 367 & 36 & 24 & & 311 \\
\hline 94 & 11 & 2 & 2,782 & 43 & & 9 & 128 & 552 & 42 & 5 & 2 & 566 \\
\hline \multirow[t]{3}{*}{298} & 140 & & 2,959 & 1,249 & & 1 & 2 & 233 & 177 & & 32 & 242 \\
\hline & 98 & 3 & 2,681 & & 1 & 141 & 2,046 & 217 & 8 & 2 & & 1,509 \\
\hline & & & 194 & 5 & & & 6 & 132 & & & & 57 \\
\hline \multirow[t]{2}{*}{1,938} & 1,827 & 171 & 72 & 1,755 & 1,709 & 12,308 & 1,442 & 3,139 & 817 & 541 & 99 & 33 \\
\hline & 157 & & 3,169 & 36 & 1,367 & 2 & 473 & 190 & 2 & & & 288 \\
\hline 446 & 218 & 17 & 4,402 & 103 & 201 & 99 & 505 & 495 & 137 & 359 & 3 & 1,204 \\
\hline 1,590 & 7 & & 819 & 411 & 8 & 302 & 3,588 & 1,216 & 262 & 239 & & 299 \\
\hline 32 & 8 & & 4,265 & & 2,165 & 602 & 65 & 427 & 4 & 1 & & 591 \\
\hline \multirow[t]{2}{*}{993} & 1,102 & 56 & 146 & 1,047 & 1,573 & 1,137 & 994 & 2 & 277 & 436 & 56 & 442 \\
\hline & 26 & & 894 & & 332 & 2 & 173 & 398 & & & & 413 \\
\hline \multirow[t]{2}{*}{20} & 182 & & 731 & 3 & 378 & & 208 & 157 & & & & 297 \\
\hline & & & 42 & & & & & 147 & & & & 34 \\
\hline \multirow[t]{2}{*}{603} & 1,325 & 14 & 50 & 228 & 441 & 711 & 808 & 1 & 48 & 47 & 1 & 8 \\
\hline & \multicolumn{12}{|c|}{ Token Bigram Frequency (Continued) } \\
\hline \multirow[t]{2}{*}{11,061} & 45,247 & 4,509 & 537 & 32,182 & 30,249 & 42,221 & 32,227 & 13,623 & 12,068 & 2,919 & 176 & 6,123 \\
\hline & & & 5,041 & & 2,816 & & & 103 & & & & 771 \\
\hline 3,443 & 2,325 & 2 & 12,902 & & 5,942 & & & 1,380 & & 1,531 & & 167,607 \\
\hline 2 & 0 & & 8,835 & & 5,393 & & & 6,455 & & & & 2,626 \\
\hline 6,607 & 42,050 & 6,985 & 3,887 & 22,461 & 37,476 & 16,175 & 20,551 & 18,535 & 3,580 & 14,498 & 493 & 2,603 \\
\hline 11 & 4 & & 1,710 & & & & & 151 & & & & 17,730 \\
\hline 19,147 & 7,278 & 260 & 4 & 932 & 8,620 & 24,646 & 12,914 & 1 & 1,167 & 905 & 489 & 0 \\
\hline 2,223 & 1,760 & & 2,938 & & 2,630 & & & 3,157 & & & & 3,353 \\
\hline 21,119 & 21,678 & 879 & 46,021 & 6,239 & 7,611 & 29,913 & 14,325 & 26 & 954 & 4,066 & 267 & 7,817 \\
\hline 268 & 585 & & 64,691 & 1,404 & 9,063 & 178 & 7,511 & 6,417 & 440 & 31 & & 3,292 \\
\hline 650 & 201 & 12 & 32,199 & 388 & & 6 & 557 & 8,778 & 514 & 4 & 26 & 8,651 \\
\hline \multirow[t]{3}{*}{4,241} & 485 & & 81,490 & 8,006 & & 2 & 0 & 1,151 & 3,408 & & 96 & 3,217 \\
\hline & 862 & 0 & 36,399 & & 0 & 974 & 16,614 & 1,168 & 1 & 0 & & 34,565 \\
\hline & & & 1,160 & 10 & & & 16 & 1,168 & & & & 1,018 \\
\hline \multirow[t]{2}{*}{26,518} & 21,459 & 648 & 691 & 17,379 & 22,113 & 190,273 & 21,577 & 101,085 & 4,656 & 6,198 & 1,222 & 580 \\
\hline & 574 & & 82,973 & 82 & 30,125 & 1 & 5,993 & 686 & 0 & & & 7,453 \\
\hline 2,695 & 4,319 & 252 & 51,273 & 192 & 995 & 297 & 2,517 & 3,427 & 941 & 6,733 & 11 & 22,478 \\
\hline 9,068 & 9 & & 11,646 & 2,815 & 124 & 2,146 & 30,367 & 20,494 & 2,686 & 5,577 & & 5,570 \\
\hline 481 & 6 & & 74,870 & & 14,373 & 1,618 & 850 & 5,154 & 18 & 1 & & 13,061 \\
\hline \multirow[t]{2}{*}{10,608} & 15,937 & 1,671 & 2,486 & 15,882 & 15,607 & 22,446 & 17,743 & 1 & 1,168 & 3,141 & 415 & 4,735 \\
\hline & 155 & & 10,774 & & 1,225 & 5 & 1,287 & 2,332 & & & & 5,277 \\
\hline \multirow[t]{2}{*}{438} & 2,832 & & 7,131 & 0 & 7,995 & & 594 & 1,517 & & & & 17,328 \\
\hline & & & 242 & & & & & 409 & & & & 73 \\
\hline 3,020 & 15,992 & 121 & 163 & 4,938 & 8,907 & 19,897 & 7,599 & 0 & 214 & 193 & 0 & 13 \\
\hline
\end{tabular}

(Manuscript received October 12, 2007;

revision accepted for publication February 4, 2008.) 